\title{
ON ZYMOIDS
}

By A. R. BEARN, AND W. CRAMER, Ph.D., Lecturer on Physiological Chemistry in the University of Edinburgh.

From the Physiological Department, University of Edinburgh

(Received February Ist, 1907)

As the result of the recent work of E. Fischer, H. E. Armstrong, E. F. Armstrong, W. M. Bayliss and others, strong evidence has been adduced in support of the view that the action of an enzyme involves the formation of an intermediate compound between the enzyme and the substrate. It appears that the reaction between enzyme and substrate proceeds in two stages, of which the first consists of the formation of the intermediate compound, while the breaking down of this compound into the products of enzyme action constitutes the second stage. If one considers the contrast between the high specificity of the enzymes towards the substrate and the similarity in the chemical changes which they bring about, the assumption that the two stages of enzyme action are related to two different parts of the enzyme molecule appears justified. Such a view would suggest that substances might possibly exist which have still retained their property of combining with the substrate without the power of destroying it. If this be so, we should expect to find that a substrate combined with a 'zymoid,' as Bayliss proposes to call such a substance, should be protected from the activity of the enzyme, provided that sufficient zymoid is present to satisfy the affinity of the substrate. While enzymes are recognised by the products of their activity, zymoids would give evidence of their existence by an inhibition of the activity of the enzyme to which they are related.

These considerations induced us to investigate whether an enzyme rendered inactive by exposure to heat would exhibit any such inhibitory influence on the activity of the unheated enzyme. When the 
results of our first experiments were published (I) we were not aware of similar experiments bearing on this question. Since then our attention has been drawn to the observations of Pollack (2) and Schwarz (3), both of whom found marked inhibition to occur, if trypsin or pepsin was made to act in the presence of the heated enzyme. Both authors agree that the inhibitory substance is not destroyed by heat, that it is indiffusible, and that it exerts its influence by in some way affecting the fermentative process. Schwarz suggests it acts as a ' negative catalyst,' since no evidence could be obtained that it directly affects either the substrate or the enzyme.

Our observations, which refer to pepsin, rennin, taka-diastase and emulsin, agree in the main point with those of Pollack and Schwarz in that the addition of heated enzyme to active enzyme produces a strong inhibition of the reaction. In many other respects, however, our investigation has led to different results, and has thrown light on the mode of action of those inhibitory substances.

\section{Experiments with Pepsin}

For these experiments various preparations were used, namely, (I) an infusion of pig's or rabbit's stomach, (2) Benger's liquor pepticus, (3) pepsin (powder), and (4) pepsin (scales). These two last preparations were obtained from Duncan and Flockhart. The pepsin solutions were rendered inactive (a) by keeping them at temperatures varying from $56^{\circ}$ to $60^{\circ}$ for twenty to thirty minutes, (b) by keeping them in a boiling water bath for an equal time. A precipitate which appeared on heating was removed by filtration; the filtrate was used for the experiments. A series of tubes was then prepared containing a constant amount of fresh active pepsin to which varying amounts of heated pepsin were added. The tubes were filled up to a constant volume with dilute $\mathrm{HCl}$ of the same concentration as the $\mathrm{HCl}$ contained in the pepsin solution. Mett's tubes were added and the mixture incubated for periods varying from eight to sixteen hours.

A typical experiment in which liquor pepticus was employed may be given here. 


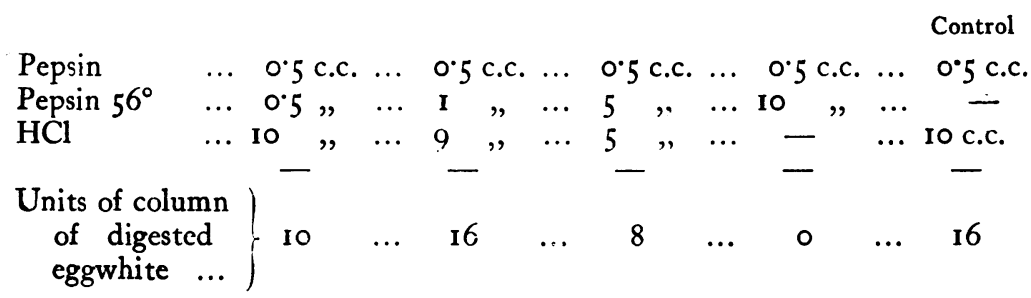

It will be seen that an excess of a solution of pepsin heated to $56^{\circ}$ produces a strong inhibition. If, however, a similar series of experiments is made with a solution of pepsin heated previously to $100^{\circ}$ for twenty minutes, the addition of the heated enzyme does not affect the action of the fresh pepsin.

\begin{tabular}{|c|c|c|c|c|c|c|c|c|}
\hline & & & & & & & & Control \\
\hline Pepsin & $\ldots$ & $\ldots$ & .. 0.5 c.c. & & c.c. & & c.c. & 0.5 c.c. \\
\hline Pepsin $100^{\circ}$ & ... & $\ldots$ & $\ldots \quad 0.5 \%$ & I & " & 5 & , & - \\
\hline $\mathrm{HCl} \ldots$ & $\ldots$ & $\ldots$ & $\ldots 95$, & 9 & $"$ & 5 & $"$ & Io c.c. \\
\hline Units of dig & ested & ggwi & $\ldots 13$ & 12 & & 14 & & 15 \\
\hline
\end{tabular}

These experiments have been repeated frequently. We have never failed to obtain strong inhibition with solutions of liquor pepticus rendered inactive by temperatures between $56^{\circ}$ and $60^{\circ}$; while similar quantities of pepsin solutions heated to $100^{\circ}$ failed to produce any inhibition at all, and, indeed, produced in some instances a more or less marked acceleration. Experiments with infusions of pig's stomach gave similar results.

In order to decide whether the inhibitory action was brought about by a substance specific for each species, pepsin solutions prepared from the stomach of the pig and the rabbit respectively were tested against each other. By measuring the digestive power of the two solutions and diluting the more active solution, the two solutions were brought to about the same concentration.

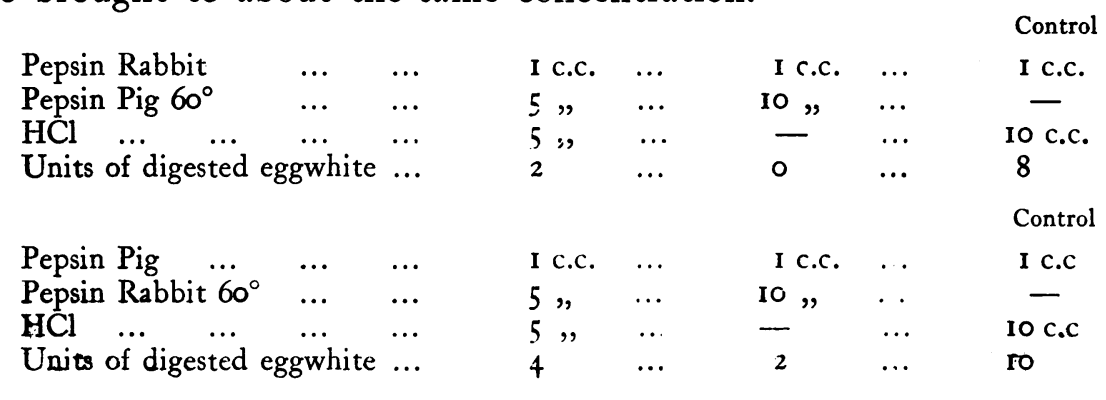


Our results agree with those of Schwarz and Pollack in showing that the inhibitory substance is not specific for each species.

Our observations on the pepsin specimens three and four (Duncan and Flockhart) which represent purer pepsin preparations, differ slightly from those detailed above. Firstly, these preparations were much more stable towards heat, so that in the case of pepsin in scales (No. 4) a solution was rendered inactive only after keeping it at $56^{\circ}$ to $60^{\circ}$ for sixteen hours. Secondly, the inhibition which could be obtained was much smaller ; in fact, with the fourth preparation (pepsin in scales) we were unable to produce an inhibition by the enzyme inactivated at $60^{\circ}$, while a solution of this preparation which had been inactivated by keeping it at $100^{\circ}$ for twenty minutes possessed strong inhibitory power.

The following examples will illustrate the behaviour of these preparations :-

$\begin{array}{llllll}\text { Pepsin (powder) } & \ldots & \ldots & \text { I c.c. } & \ldots & \text { Control } \\ \text { Pepsin (powder) } 60^{\circ} & \ldots & \text { 10 }, & \ldots & - \\ \text { HCl } \ldots & \ldots & \ldots & - & \ldots & \text { 10 }, \\ \text { Digested eggwhite } & \ldots & 25 & \ldots & 30\end{array}$

The addition of enzyme exposed to $100^{\circ}$ for ten minutes not only failed to inhibit the action of the enzyme, but actually increased the digestive power.

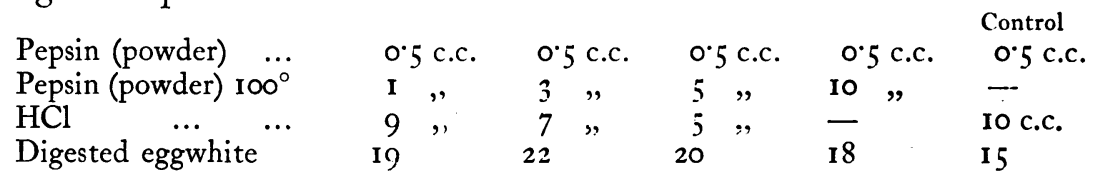

The behaviour of this pepsin preparation stands in striking contrast to that of the pepsin in scales.

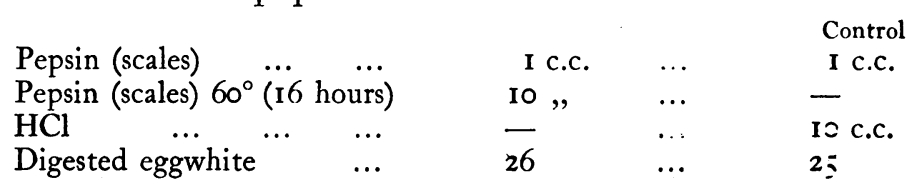

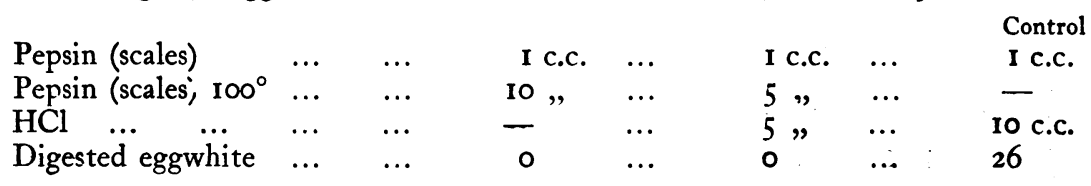

The significance of these differences will be discussed later on. 
The inhibitory substances do not easily dialyse through parchment tubes (Schleicher and Schüll's 'Diffusions-Hülsen'). After three days the dialysate did not produce any inhibition. When the process was continued for three weeks the dialysate possessed distinct inhibitory properties.

\section{RenNin}

The experiments with rennin were made with various rennin preparations, which were procured from neighbouring chemists. The enzyme solutions were heated in the same way as has been described for pepsin, and a similar series of experiments was arranged.

The results which we obtained at first were very irregular. In some cases a distinct inhibition was observed if rennin heated to $60^{\circ}$ was present, while in others we failed entirely to get any evidence of an inhibitory action. It was noticed, however, that by mixing the various reagents in a definite order, so that the active rennin was added last, the results became much more regular, and inhibition was found to occur more frequently.

The following experiments, in which the rennin was added last, may serve as an example :-

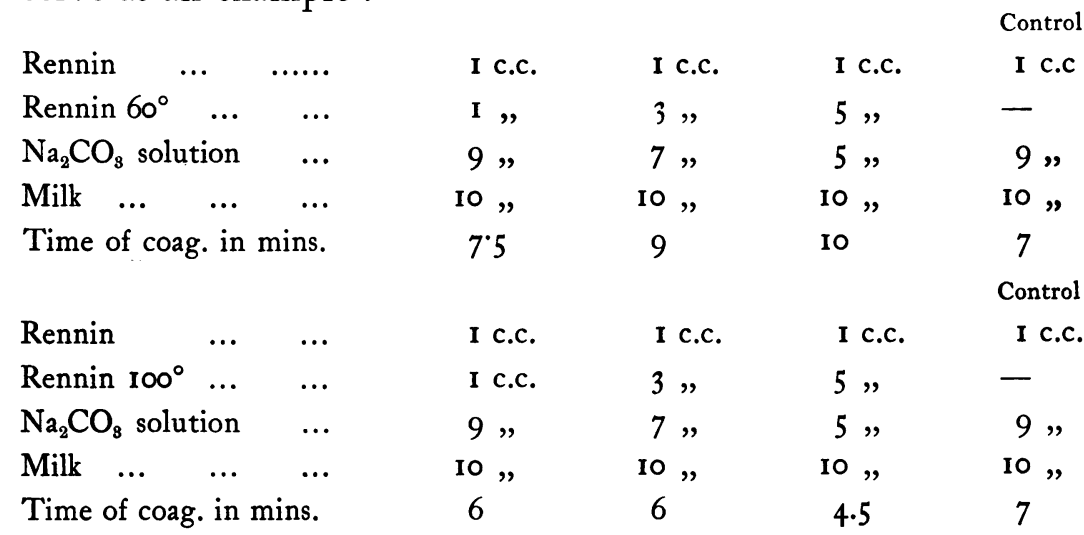

It will be seen that there is a distinct inhibition produced by adding an excess of rennin heated to $60^{\circ}$, while a solution of rennin heated to $100^{\circ}$ is devoid of any inhibitory power ; on the contrary, like pepsin, it may enhance the activity of the enzyme. 
How great the difference is between adding the inhibitory substance before or after the addition of active rennin may be seen from the following experiments where two sets of four tubes each were filled with a mixture of definite amounts of $\mathrm{Na}_{2} \mathrm{CO}_{3}$ solution and milk. In one set rennin was added first, and immediately afterwards the heated enzyme. In the other set the order of adding active and inactivated enzyme was reversed.

\begin{tabular}{|c|c|c|c|c|c|}
\hline & & & & & Control \\
\hline Rennin & $\ldots$ & I c.c. & I c.c. & I c.c. & I c.c. \\
\hline Rennin $60^{\circ} \quad \ldots$ & $\ldots$ & I & 3 & 5, & - \\
\hline $\mathrm{Na}_{2} \mathrm{CO}_{3}$ solution & $\ldots$ & 9 & 7 & $5 "$ & $9 "$ \\
\hline Milk $\quad \ldots$ & $\ldots$ & Io , & 10, & 10, & Io , \\
\hline
\end{tabular}

Time of coag. in mins.

$\begin{array}{lrlll}\text { Active rennin added first } & 2 \cdot 5 & 1 \cdot 75 & 2 & 6 \\ \text { Heated rennin added first } & 5 & 7 \cdot 5 & 9 \cdot 5 & 6\end{array}$

The difference is very distinct, even if the acceleration which was observed in the one set of experiments is neglected. ${ }^{1}$

By keeping the heated rennin in contact with the milk for some time before the addition of active rennin, the inhibition became even more marked, as will be seen from the following experiment :-

A mixture 5 c.c. milk +5 c.c. rennin, $60^{\circ},+5$ c.c. $\mathrm{Na}_{2} \mathrm{CO}_{3}$ solution, was prepared and divided into two halves. To one half I c.c. active rennin was added. Clotting occurred after nine minutes. The other half was left standing at room temperature for five minutes, then I c.c. of active rennin was added. Clotting occurred after 17.5 minutes.

No increase of the inhibition was observed if the active rennin was kept for five minutes in contact with heated rennin before the milk was added.

The inhibitory action of heated rennin solutions is, however, by no means a constant phenomenon. With some rennin preparations we have entirely failed to get any evidence of a retarded clotting of milk. These irregularities recall the behaviour of the different pepsin preparations.

I We are at present unable to give an explanation of this accelerating effect, which has been observed frequently although by no means regularly. An analogous effect was sometimes observed in the case of pepsin, when the amount of heated pepsin added was insufficient to produce inhibition. 
In order to decide whether the inhibition produced by heated enzyme is a property common to most ferments, we investigated the behaviour of taka-diastase towards starch and emulsin towards lactose.

\section{TAKA-Diastase}

A preparation by Parke, Davis \& Co. was used throughout. The enzyme action was measured by Croft-Hill's modification of Pavy-Fehling's method.

\begin{tabular}{|c|c|c|c|c|c|c|}
\hline Taka-diastase & $\ldots$ & $\ldots$ & I c.c. & $\ldots$ & I & c.c. \\
\hline Taka-diastase $60^{\circ}$ & $\ldots$ & $\ldots$ & Io , & $\ldots$ & - & \\
\hline Starch solution & $\ldots$ & $\ldots$ & $5 \%$ & $\ldots$ & 5 & ", \\
\hline Water $\quad \ldots$ & ... & $\ldots$ & - & ... & Io & ", \\
\hline \multicolumn{7}{|c|}{ C.c. of mixture required to reduce Ic c.c. copper solution } \\
\hline Before incubation & $\ldots$ & $\ldots$ & 9 c.c. & $\ldots$ & - & \\
\hline After incubation $\mathrm{fc}$ & for four & r hours & $7 \cdot 2$, & .. & $5 \% 9$ & " \\
\hline Taka-diastase & $\ldots$ & $\ldots$ & 2 c.c. & $\ldots$ & 2 & $"$ \\
\hline Taka-diastase $60^{\circ}$ & & $\ldots$ & 10 ", & $\ldots$ & - & \\
\hline Starch solution & ... & $\cdots$ & 5 & $\cdots$ & 5 & $"$ \\
\hline Water $\quad \ldots$ & $\ldots$ & $\ldots$ & - & $\ldots$ & IO & ", \\
\hline
\end{tabular}

Before incubation ... $\quad \ldots \quad \ldots$ I9.5 c.c. ...

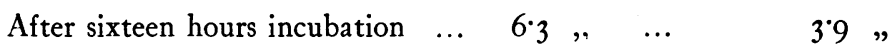

All our experiments with this preparation of taka-diastase gave positive results.

The behaviour of taka-diastase heated to $100^{\circ}$ was not investigated.

\section{EMULsin}

A preparation by Merck was used. The activity of the enzyme was measured by the method employed for taka-diastase.

\begin{tabular}{|c|c|c|c|c|}
\hline Emulsin $\quad \ldots$ & $\ldots$ & I c.c. & $\ldots$ & I c.c. \\
\hline Emulsin $60^{\circ}$ & $\ldots$ & 10 , & $\ldots$ & - \\
\hline Lactose solution & $\ldots$ & I0 ", & $\ldots$ & 10 \\
\hline Water & $\ldots$ & - & $\ldots$ & I0 \\
\hline C.c. of mixture & required to & e 10 c.c. & pper & \\
\hline Before incubation & $\ldots \quad \ldots$ & I.8 c.c. & $\ldots$ & - \\
\hline After twenty hou & rs incubation & I. $5 \%$ & $\ldots$ & 0.8 \\
\hline
\end{tabular}


All our experiments with emulsin gave evidence of a distinct inhibition due to the presence of heated enzyme. The inhibitory effect remained even after keeping a solution of emulsin at $100^{\circ}$ for forty-five minutes.

$\begin{array}{lllllll}\text { Emulsin } & \ldots & \ldots & \ldots & \text { I c.c. } & \ldots & \text { I c c. } \\ \text { Emulsin } 100^{\circ} & \ldots & \ldots & \text { I0 }:, & \ldots & - \\ \text { Lactose solution } & \ldots & \ldots & \text { I0 }, & \ldots & \text { Io }, \\ \text { Water } & \ldots & \ldots & \ldots & - & \ldots & \text { Io }\end{array}$

General Discussion of our Results

Our results show that in the case of the enzymes investigated the addition of an excess of an enzyme which has been inactivated by heat may produce a distinct inhibition of the action of the unheated enzyme. In that respect they confirm and extend the observations of Schwarz and Pollack. We find, however, that this phenomenon may be exhibited in varying degrees by different preparations of the same enzyme, so that even absolutely negative results may be obtained. We are informed, too, that independent observers have repeated the observations of Schwarz and Pollack and have failed to obtain evidence of any inhibition. Any attempt to explain the positive results must take into account these apparent failures.

A great many observations are on record dealing with substances which inhibit enzyme action by combining with the enzyme. Our observations agree with those of Schwarz and Pollack in showing that the inhibitory effect of heated enzymes is not brought about in this way, and that the effect of heated enzyme solutions is, therefore, not due to the presence of anti-enzymes. These two observers have been unable to trace this effect of heated pepsin or trypsin solutions back to an action of the heated enzyme on the substrate, and on the basis of this negative evidence they conclude that the inhibition depends on a substance acting as a ' negative catalyst.' Our experiments with rennin show that the inhibitory substances act directly on the substrate. They conform to the condition stated in the 
introduction as supplying evidence for the existence of 'zymoids.' The existence of such substances has already been postulated by Korschun (4) and by Bayliss (5), but on different grounds.

The first-named author applied the method devised by Ehrlich for the standardisation of diphtheria antitoxin to rennin solutions filtered through a Berkefeld filter. By determining the minimal active dose and the dose completely neutralising anti-rennin he found that a decrease in the value of the first factor was not accompanied by a corresponding decrease in the value of the second factor-in other words that the activity of the rennin as measured by the clotting of milk was more affected than its power to combine with its antibody. These results which are analogous to those obtained by Ehrlich for simple lethal dose and $\mathrm{L}_{0}$ dose in the case of diphtheria toxin led Korschun to conclude that rennin contains substances analogous to the toxoids of diphtheria toxin. In observing the change in the conductivity when heated trypsin was allowed to act on gelatine, Bayliss found a fall in the conductivity to occur instead of the rise which takes place with normal trypsin and represents the breaking down of the intermediate compound. He interpreted this phenomenon as showing the presence of a body which retained its power of combination with the substrate while becoming comparatively inactive as regards the decomposition of the substrate.

Our results support the view of these authors, and adduce new evidence in its support. The existence of these zymoids in heated enzyme solutions may be explained by assuming that the enzyme has been converted into the zymoid, the heat having destroyed its proteoclastic power. But this view, which is the view we adopted in our first communication, does not afford an explanation of the different behaviour of different enzyme preparations. Nor does it agree with the observations of Korschun. We are, therefore, inclined to assume that the zymoids are preformed in the enzyme preparations, but that their presence is not recognised until they are unmasked by the destructive action of heat on the enzyme. Zymoids exist even if the preparations are obtained directly from the organism : they may have been formed by the cells or they may be ultimately derived 
from the enzyme, which may have been converted into these bodies by agencies more subtle than sudden exposure to heat. This view does not exclude the possibility that the enzyme is converted into a zymoid by the action of heat. But the zymoids thus formed become merely superadded to those already existing. Different enzyme preparations vary in their composition, some containing more, others less zymoids. The difference in their behaviour towards heat is similar to that exhibited by different preparations of an active enzyme.

\section{Conclusions}

Solutions of enzymes which have been heated to $56^{\circ}$ to $60^{\circ}$ for twenty to thirty minutes have a strongly inhibitory effect on the activity of the unheated enzyme, if a sufficiently great amount of heated enzyme is present.

The inhibition is destroyed, as a rule, by exposure to $100^{\circ}$; in some cases, however, it may persist.

Different preparations of the same enzyme vary in the inhibitory power which they exhibit after exposure to heat.

The inhibition is not due to an anti-ferment. It is brought about by a reaction between the substrate and substances present in the inactivated enzyme.

These substances dialyse only very slowly through parchment. In the case of pepsin they are not specific for each species.

These facts point to the existence of zymoids, which are probably preformed in the enzyme preparations. Zymoids, like enzymes, differ in their resistance towards heat.

Different enzyme preparations vary in the amount of zymoids which they contain.

(I) W. Cramer and A. R. Bearn, Proc. Pbys. Soc., June, 1906, p. 36; Fourn. of Pbysics, Vol. XXXVI.

(2) L. Pollack, Beitraege z. cbem. Physiol. u. Patbol., Vol. V, 1904, p. 95-I 12.

(3) O. Schwarz, Beitraege z. cbem. Pbysiol. u. Patbol., Vol. VI, 1905, p. 524-542.

(4) S. Korschun, Zeitscbrift f. Physiol. Cbemie, Vol. XXXVII, 1903, p. 366.

(5) W. M. Bayliss, Arcbives d. Sciences Biologiques, Vol. XI (Supplement), 1904, p. 26I (St. Petersburg). 